\title{
Statins as New Therapeutic Agent for Ebola Viral Disease: Fact or Fallacy
}

\author{
Beuy Joob ${ }^{1}$, Viroj Wiwanitkit ${ }^{2}$ \\ ${ }^{1}$ Sanitation 1Medical Academic Center, Bangkok Thailand \\ ${ }^{2}$ Visiting professor, Hainan Medical University, China; adjunct professor, Joseph \\ Ayobabalola University, Nigeria \\ beuyjoob@hotmail.com
}

Dear Editor,

The Ebola viral disease is the serious infection that becomes the global health concern. The recent outbreak in Africa leads several attempts to develop new treatment. Several drugs are proposed as new therapeutic agent. Statins has been recently proposed as new immune modulating drugs that can be useful for management of Ebola viral disease [1 -2]. In general, statin is the specific group of drug mainly used for management dyslipidemia. Statin is usually mentioned that statin helps modify host response and result in decrease vascular endothelial pathology. In rat model, it is well proved that statin help stabilize and regenerate of vascular pathology by chemokine modulation process [3]. Greenwood and Mason concluded that statin help "attenuate endothelial MHC class II expression, increase endothelial nitric oxide synthase and fibrinolytic activity, decrease leukocyte adhesion and transmigration, and enhance resistance to local injurious stimuli [4]." Fedson and his team mentioned for the success of using statins in managing the infected cases in Africa [1 -2]. It becomes the new focus issue to be further clarified [5]. Indeed, there are several concerns on the pharmacological effect and advantage of statins in Ebola viral disease. First, if the immunomodulation is actually useful, there should be no infection in any dyslipidemia receiving statin therapy. Second, although statins are reported for activity to kill virus (such as poliovirus [6]), there has never report on this property on Ebola virus. For endothelial protection, although statins are mentioned and used by many cardiologists, it has never been proved or recommended by infectious medicine experts. In conclusion, based on present clinical evidences, it is still not a fact that simvastatin can be effective for management of Ebola viral disease.

\section{REFERENCES}

[1] Fedson DS, Rordam OM. Treating Ebola patients: a 'bottom up' approach using generic statins and angiotensin receptor blockers. Int J Infect Dis. 2015 Jul;36:80-4.

[2] Fedson DS, Jacobson JR, Rordam OM, Opal SM. Treating the Host Response to Ebola Virus Disease with Generic Statins and Angiotensin Receptor Blockers.MBio. 2015 Jun 23;6(3):e00716.

[3] Kesavan M, Sarath TS, Kannan K, Suresh S, Gupta P, Vijayakaran K, Sankar P, Kurade NP, Mishra SK, Sarkar SN.Atorvastatin restores arsenic-induced vascular dysfunction in rats: modulation of nitric oxide signaling and inflammatory mediators.ToxicolApplPharmacol. 2014 Oct 1;280(1):107-16.

[4] Greenwood J, Mason JC.Statins and the vascular endothelial inflammatory response.Trends Immunol. $2007 \mathrm{Feb}$;28(2):88-98.

[5] Patanè S.Ebola: is there a hope from treatment with cardiovascular drugs?Int J Cardiol. 2014 Dec 15;177(2):524-6.

[6] Liu S, Rodriguez AV, Tosteson MT.Role of simvastatin and methyl-beta-cyclodextrin [corrected] on inhibition of poliovirus infection.BiochemBiophys Res Commun. 2006 Aug 18;347(1):51-9. 